\title{
Retrieval induces hippocampal-dependent reconsolidation of spatial memory
}

\author{
Janine I. Rossato, Lia R.M. Bevilaqua, Jorge H. Medina, Iván Izquierdo, and \\ Martín Cammarota ${ }^{1}$
}

\begin{abstract}
Centro de Memória, Instituto de Pesquisas Biomédicas, Pontifícia Universidade Católica do Rio Grande do Sul, Porto Alegre, RS, Brasil; Laboratorio de Neuroreceptores, Instituto de Biología Celular y Neurociencias "Prof. Dr. Eduardo de Robertis," Facultad de Medicina, Universidad de Buenos Aires, Ciudad Autónoma de Buenos Aires, Argentina \& Instituto de Ciências Básicas da Saúde, Departamento de Bioquímica, Universidade Federal do Rio Grande do Sul, Porto Alegre, RS, Brasil
\end{abstract}

\begin{abstract}
Nonreinforced retrieval can cause extinction and/or reconsolidation, two processes that affect subsequent retrieval in opposite ways. Using the Morris water maze task we show that, in the rat, repeated nonreinforced expression of spatial memory causes extinction, which is unaffected by inhibition of protein synthesis within the CAl region of the dorsal hippocampus. However, if the number of nonreinforced retrieval trials is insufficient to induce long-lasting extinction, then a hippocampal protein synthesis-dependent reconsolidation process recovers the original memory. Inhibition of hippocampal protein synthesis after reversal learning sessions impairs retention of the reversed preference and blocks persistence of the original one, suggesting that reversal learning involves reconsolidation rather than extinction of the original memory. Our results suggest the existence of a hippocampal protein synthesis-dependent reconsolidation process that operates to recover or update retrieval-weakened memories from incomplete extinction.
\end{abstract}

Consolidation is the protein synthesis-dependent process that stabilizes new memories and makes them resistant to pharmacological and traumatic disruption (McGaugh 1966). Since the observation that trained animals re-exposed to reminder cues along with hypothermia or electroconvulsive shock show diminished retrieval (Misanin et al. 1968; Lewis et al. 1972), several authors have suggested that at the time of retrieval consolidated memories become vulnerable again (Przybyslawski and Sara 1997; Przybyslawski et al. 1999). It was proposed that in order to endure after retrieval, memories must undergo a further round of protein synthesis-dependent stabilization called reconsolidation (Nader et al. 2000a; Nader 2003; Eisenberg and Dudai 2004).

This hypothesis is based on the original finding that intraamygdala administration of the protein synthesis inhibitor anisomycin (ANI) at the time of retrieval hinders memory expression of one form of fear conditioning in succeeding sessions (Nader et al. 2000a). Since then, several laboratories have found similar results with other paradigms in different animal models, and using other inhibitory treatments given systemically or into other brain regions (Debiec et al. 2002; Kida et al. 2002; Pedreira et al. 2002; Eisenberg et al. 2003; Sangha et al. 2003; Lee et al. 2004; Gainutdinova et al. 2005; Inda et al. 2005; Merlo et al. 2005; Stollhoff et al. 2005). In a few cases, the effect of potentially stimulant treatments (strychnine, cocaine, glucose, fructose, and PKA activators) on memory reconsolidation has also been studied (Rodriguez et al. 1993; Horne et al. 1997; Tronson et al. 2006).

It has been earlier proposed (Nader et al. 2000b; Sara 2000; Dudai 2002) and recently reported (Frenkel et al. 2005; Rodriguez-Ortiz et al. 2005; Tronson et al. 2006) that reconsolidation might serve not only to maintain but also to strengthen or update retrieved memories. Despite all this, the reconsolidation hypothesis is not unanimously accepted, and several laboratories,

\footnotetext{
${ }^{1}$ Corresponding author.
}

E-mail mcammaro@terra.com.br; fax 55-51-33203312.

Article is online at http://www.learnmem.org/cgi/doi/10.1101//m.315206. including ours, have failed to detect it in well-known learning paradigms (Dawson and McGaugh 1969; Squire et al. 1976; Biedenkapp and Rudy 2004; Cammarota et al. 2004; Hernandez and Kelley 2004; Lattal and Abel 2004; Mileusnic et al. 2005; Power et al. 2006).

In particular, two issues are still matters of intense debate. First, nonreinforced retrieval has long been known to initiate memory extinction (Pavlov 1927; Rescorla 2001). Second, many studies reported that the impairment produced by post-retrieval treatments is short-lasting, with recovery of memory occurring within hours or days (Judge and Quartermain 1982; Vianna et al. 2001; Anokhin et al. 2002; Lattal and Abel 2004). Unless those changes are shown to last (e.g., Debiec et al. 2002; Milekic and Alberini 2002; Izquierdo and Cammarota 2004; Lee et al. 2004) or, alternatively, are demonstrated to result from a time- and brain region-dependent process, it will be difficult to determine conclusively whether the amnesia induced by post-retrieval treatments represents a disruption of memory storage, an enhancement of extinction, or just a temporary performance effect.

The hidden-platform version of the Morris water maze task (MWM) is perhaps the paradigm most utilized to analyze the participation of the hippocampus in spatial memory (Bures et al. 1997; Redish and Touretzky 1998; De Hoz et al. 2004; Schimanski and Nguyen 2004). It has been reported that in rats the intracerebroventricular infusion of the protein synthesis inhibitor anisomycin (ANI) blocks acquisition of the memory associated with this task (Meiri and Rosenblum 1998), and that in mice intraperitoneal (Suzuki et al. 2004) but not subcutaneous (Lattal and Abel 2001; Lattal et al. 2004) ANI hinders reconsolidation and extinction. However, at present there are no studies about the consequences of hippocampal protein synthesis inhibition in the consolidation and post-retrieval persistence of the MWM memory. Therefore, here we investigated the effect of the intrahippocampal infusion of ANI on the retention and post-retrieval stability of the memory for a spatial preference in the MWM learning task. 


\section{Results}

\section{Post-training intra-hippocampal infusion}

\section{of ANI blocks spatial memory retention}

First, we determined whether protein synthesis is indeed required in the hippocampus for consolidation of the memory for the spatial (hidden platform) version of the MWM. Bilateral infusion of the protein synthesis inhibitor anisomycin (ANI; $160 \mu \mathrm{g} / \mathrm{side}$ ) into the CA1 region of the dorsal hippocampus immediately after each daily training session blocked the improvement in latency to find the platform seen in vehicle-infused animals (Fig. 1A) $\left(F_{(1,20)}=83.21 ; P<0.001\right)$. A probe test in the absence of the escape platform carried out $24 \mathrm{~h}$ after the last training session confirmed that ANI blocked consolidation of the MWM memory. Rats that received vehicle during training spent more time searching in the target quadrant than those given ANI, which showed no spatial preference for any quadrant $\left(t_{(20)}=11.61\right.$; $P<0.001$ vs. VEH, Fig. 1B). The effect of ANI was completely reversible, and the animals normally acquired the memory for the task once the post-training infusions were halted (not shown).

ANI $(160 \mu \mathrm{g} / \mathrm{side})$ did not affect spatial memory retention when given into CA1 at $3 \mathrm{~h}\left(F_{(1,14)}=0.68 ; P>0.1\right.$, Fig. $1 \mathrm{C}$ and $t_{(14)}=0.38 ; P>0.1$, Fig. 1D) or $6 \mathrm{~h}\left(F_{(1,14)}=3.87 ; P>0.1\right.$, Fig. $1 \mathrm{E}$ and $t_{(14)}=0.10 ; P>0.1$, Fig. $\left.1 F\right)$ after the end of each training session. Moreover, intra-CA1 ANI $(160 \mu \mathrm{g} / \mathrm{side})$ had no effect on retention of the memory for the nonspatial version of the MWM task $\left(F_{(1,14)}=0.69 ; P>0.1\right.$, Fig. $\left.1 \mathrm{G}\right)$.

\section{Intra-hippocampal infusion of ANI after a single nonreinforced retrieval session blocks subsequent memory retention}

We next examined whether inhibition of hippocampal protein synthesis after nonreinforced retrieval had any effect in the persistence of the memory for the MWM. To that end, rats that had been trained for $5 \mathrm{~d}$ in the spatial version of the task were submitted to a probe test either 24 or $120 \mathrm{~h}$ after the last training session and, immediately following that, received bilateral intra-

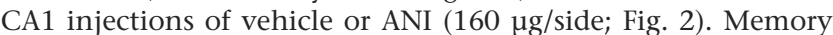
retention was evaluated in a second probe test carried out either at 2,24 , or $120 \mathrm{~h}$ after the first one. ANI reduced to chance levels the time spent in the target quadrant during the second probe test regardless of the time spanned between the last training trial and the first probe test or between the first and the second probe test, except for those animals exposed to the second probe test 2 $\mathrm{h}$ after the first one (Fig. 2A,B). ANI had no effect on memory retention when infused into CA1 at $24 \mathrm{~h}$ (Fig. 2C) or $120 \mathrm{~h}$ (Fig. 2D) post-training in the absence of a behaviorally relevant event or when injected in that hippocampal region immediately after a test session carried out $24 \mathrm{~h}$ (Fig. 2E) or $120 \mathrm{~h}$ (Fig. 2F) after training in the presence of the escape platform. Moreover, ANI did not affect subsequent memory retention when infused into CA1 at $3 \mathrm{~h}$ (Fig. 3A,B) or $6 \mathrm{~h}$ (Fig. 3C,D) after a probe test carried out 24 or $120 \mathrm{~h}$ post-training.

\section{Intra-hippocampal infusion of ANI after a series of consecutive nonreinforced retrieval sessions does not affect extinction but blocks spontaneous recovery of the spatial preference.}

There are just two explanations for the results presented above: Either nonreinforced retrieval induces memory reconsolidation, which is blocked by intra-CA1 ANI, or ANI given into CA1 after nonreinforced retrieval enhances memory extinction. Earlier reports on the effect of protein synthesis inhibition in memory extinction do not help to decide between these two possibilities. It has been shown that protein synthesis inhibitors block extinction of different memory types (Vianna et al. 2001; Myers and Davis 2002; Bahar et al. 2003; Santini et al. 2004), although it has also been reported that, under certain conditions, inhibition of protein synthesis might actually enhance memory extinction (Fischer et al. 2004).

To conciliate these findings with the reconsolidation hypothesis, it has been proposed that, depending on the strength of the reactivated trace or the number and/or length of the nonreinforced sessions, retrieval would initiate two competing processes, extinction and reconsolidation, with the dominant one being the most affected by protein synthesis inhibition (Nader 2003; Dudai 2004).

Therefore, to analyze this issue further, rats trained in the MWM were submitted to either 16 , eight, or four consecutive 60 -sec probe tests (Fig. 4). Sixteen probe tests induced complete extinction of the spatial preference $\left(F_{(15,210)}=18.19 ; P<0.001\right.$ in repeated measures ANOVA; Fig. 4A-Day 1$)$. Extinction was still clearly evident $24 \mathrm{~h}$ later and was unaffected by ANI given into CA1 immediately after the last probe test $\left(t_{(14)}=0.60 ; P>0.1\right.$ vs. VEH in the first test of Day 2; Fig.4A-Day 2). Eight consecutive probe tests also induced extinction $\left(F_{(7,147)}=25.40 ; P<0.001\right.$ in repeated measures ANOVA; Fig. 4B-Day 1), but $24 \mathrm{~h}$ later there was partial recovery of the original memory that was completely blocked by ANI given into CA1 immediately after the eighth probe test $\left(t_{(20)}=2.63 ; P<0.05\right.$ vs. VEH in the first test of Day 2 ; Fig. 4B-Day 2).

The blocking effect of ANI on recovery of the original memory was even more evident when this drug was infused into CA1 after just four extinction sessions. As can be seen in Figure $4 \mathrm{C}$, four consecutive probe tests reduced the time spent in the target quadrant $\left(F_{(3,57)}=18.67 ; P<0.001\right.$ in repeated measures ANOVA), but $24 \mathrm{~h}$ later the original memory fully recovered, leaving no remnants of extinction in control animals. However, spontaneous recovery did not occur in rats that received intraCA1 ANI immediately after the fourth extinction session $\left(t_{(18)}=4.41 ; P<0.001\right.$ vs. VEH in the first test of Day 2; Fig. $4 \mathrm{C}-$ Day 2).

\section{Intra-hippocampal infusion of ANI after reversal learning blocks retention}

\section{of both original and reversed spatial preferences}

If after MWM learning is established the hidden platform is moved to the opposite quadrant of the training pool, the animals need to replace the original spatial map by a new one in order to still be able to escape from the water. Reversal learning has been taken to imply a special form of extinction that, instead of being expressed as disappearance of the original response, is manifested as a new spatial preference (Lattal et al. 2004). However, it is clear that acquisition of the reversed response strongly relies on knowledge about the original position of the platform and on other, nonspatial, procedural components of the task, including swimming and climbing to the escape platform, as well as the awareness of such a possibility. In fact, reversal learning is fast, suggesting that it preserves part of the original mnemonic trace and accrues to it information about the novel position of the platform, thus representing an experimental situation during which new data are added to a well consolidated trace, and, hence, reconsolidation would be expected to occur (Sara 2000; Nader 2003).

Therefore, we decided to analyze whether reversal learning results from extinction of the original memory or if it is a consequence of a process that puts the original trace in a vulnerable state to allow its reconsolidation into an updated spatial prefer- 
ence. We reasoned that if reversal learning involved extinction of the original trace, then inhibition of extinction should impair the reversed preference, leaving unaffected the original memory; i.e., a treatment able to block reversal learning should allow reinstatement of the original response. On the contrary, if reversal learning was a consequence of original memory reconsolidation, then inhibition of this process should hamper both retention of the reversed preference and persistence of the original one; i.e., a treatment able to block reversal learning should also impede reinstatement of the original memory. To answer this question, rats were trained in the MWM for $5 \mathrm{~d}$. On day 6 the escape
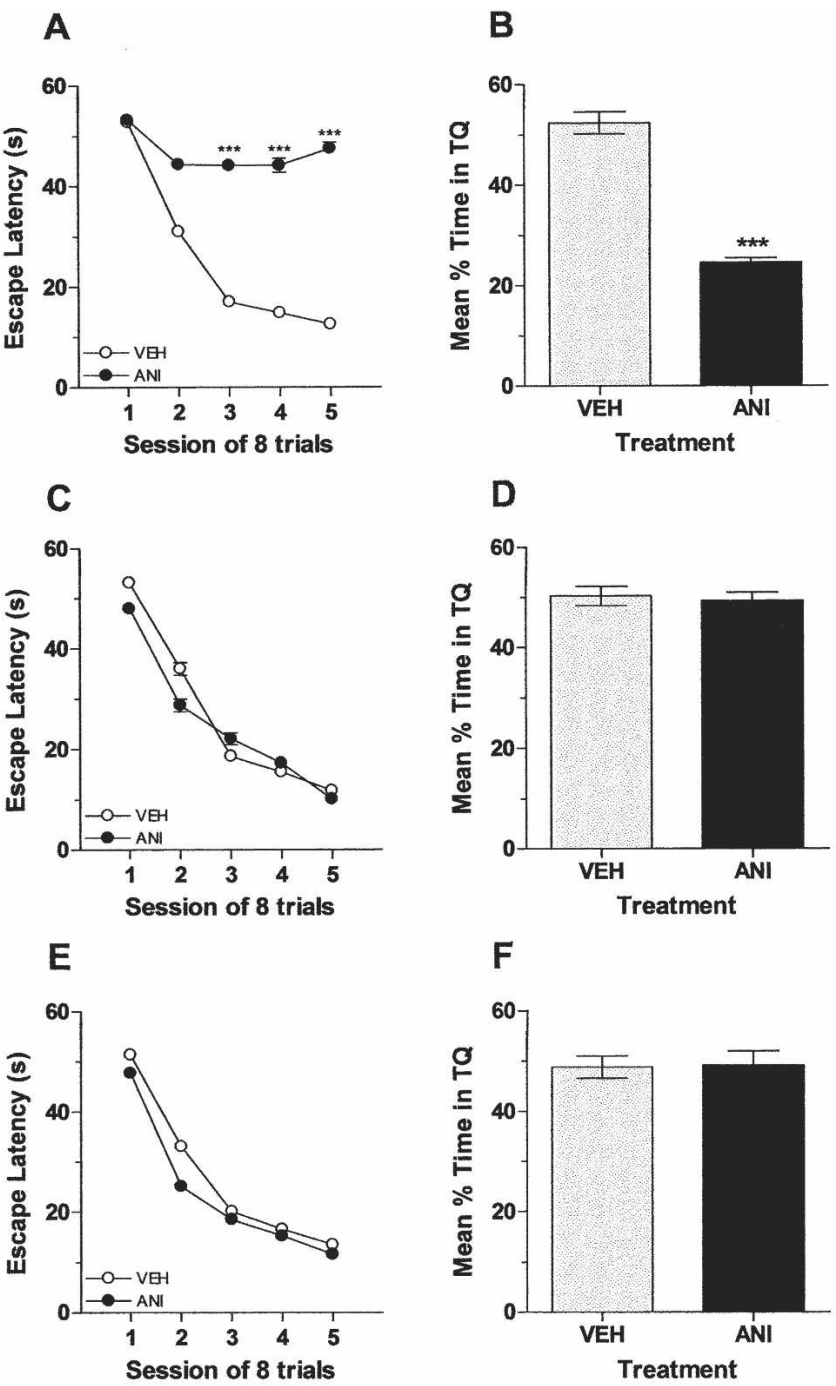

G

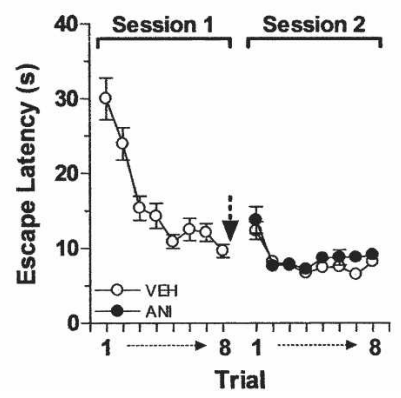

platform was moved to the opposite quadrant of the pool, and the animals were given eight consecutive trials to find the platform in its new location. Immediately after that, they received bilateral intra-CA1 infusions of vehicle or ANI (160 $\mu \mathrm{g} /$ side; Fig. $5 \mathrm{~A})$. Memory retention was evaluated in a probe test carried out either at 2, 24, or $120 \mathrm{~h}$ after reversal learning.

Rats that received vehicle acquired the reversed spatial preference, but those given intra-CA1 ANI failed to do so $\left(t_{(36)}=3.54\right.$; $P<0.01$ vs. VEH at $+24 \mathrm{~h}$ and $t_{(20)}=2.49 ; P<0.05$ vs. VEH at +120 h; Fig. 5B). The effect of ANI was not seen when the animals were tested $2 \mathrm{~h}$ post-training $\left(t_{(22)}=1.06 ; P>0.1 \mathrm{vs}\right.$. $\mathrm{VEH}$ at $+2 \mathrm{~h}$; Fig. 5B), suggesting that ANI-induced amnesia is not immediate. Interestingly, the animals that received ANI did not show preference for the initial quadrant either, indicating that reinstatement of the original memory had also been hindered (Fig. 5B, $+24 \mathrm{~h}$ and $+120 \mathrm{~h}$ ).

\section{Discussion}

The results show that:

1. When injected into dorsal CA1 immediately but not 3 or $6 \mathrm{~h}$ after training in the MWM, ANI blocks retention of spatial memory.

2. ANI given into dorsal CA1 after a single probe test 24 or $120 \mathrm{~h}$ post-training hinders retention during a second probe test carried out 24 or $120 \mathrm{~h}$ but not $2 \mathrm{~h}$ after the first one; the effect was time-dependent and contingent with the nonreinforced retrieval of the mnemonic trace.

3. ANI does not affect extinction, but blocks spontaneous recov-

Figure 1. Protein synthesis is required in the dorsal hippocampus during a restricted post-training time window for consolidation of spatial memory in the Morris water maze. $(A)$ Mean escape latencies during the $5 \mathrm{~d}$ of acquisition of spatial learning of rats given anisomycin $(160 \mu \mathrm{g} /$ side; $\mathrm{ANI}$, black circles) or vehicle (VEH, white circles) in the CA1 region of the dorsal hippocampus immediately after each session. Data are presented in blocks of eight trials as mean $\left( \pm\right.$ SEM). ${ }^{* * *} P<0.001 \mathrm{vs}$. VEH in Bonferroni post hoc test after two-way ANOVA; $n=11$ per group. (B) Mean time spent in the target quadrant (TQ) during a $60-\mathrm{sec}$ probe test carried out $24 \mathrm{~h}$ after the fifth training day for rats that received anisomycin $(160 \mu \mathrm{g} /$ side; $\mathrm{ANI}$, black bar) or vehicle (VEH, white bar) in the CA1 region of the hippocampus as in $A$. Data are presented as mean ( \pm SEM). ${ }_{* * *} P<0.001$ vs. VEH in two-tailed Student's $t$-test; $n=11$ per group. $(C)$ Animals were trained as in $A$ but received anisomycin $(160 \mu \mathrm{g} / \mathrm{side}$; ANI, black circles) or vehicle (VEH, white circles) $3 \mathrm{~h}$ after the last trial of each one of the five training sessions. Data are presented in blocks of eight trials as mean $( \pm \mathrm{SEM}) . F_{(1,14)}=0.68 ; P>0.1$ for treatment in two-way ANOVA; $n=8$ per group. (D) Mean time spent in the target quadrant (TQ) during a 60 -sec probe test carried out $24 \mathrm{~h}$ after the fifth training day for rats that received anisomycin $(160 \mu \mathrm{g} / \mathrm{side}$; ANI, black bar) or vehicle (VEH, white bar) in the CA1 region of the hippocampus as in C. Data are presented as mean $\left( \pm\right.$ SEM). $t_{(14)}=0.38 ; P>0.1$ in two-tailed Student's $t$-test; $n=8$ per group. $(E)$ Animals were trained as in $A$ but received anisomycin (160 $\mathrm{\mu g} / \mathrm{side}$; $\mathrm{ANI}$, black circles) or vehicle $(\mathrm{VEH}$, white circles) $6 \mathrm{~h}$ after each training session. Data are presented in blocks of eight trials as mean $\left( \pm\right.$ SEM). $F_{(1,14)}=3.87 ; P>0.1$ for treatment in two-way ANOVA; $n=8$ per group. $(F)$ Mean time spent in the target quadrant (TQ) during a 60 -sec probe test carried out $24 \mathrm{~h}$ after the fifth training session for rats that received anisomycin $(160 \mu \mathrm{g} / \mathrm{side}$; ANI, black bar) or vehicle (VEH, white bar) in the CA1 region of the hippocampus as in $E$. Data are presented as mean $( \pm S E M) . t_{(14)}=0.10 ; P>0.1$ in twotailed Student's $t$-test; $n=8$ per group. $(G)$ Mean escape latencies during two training sessions in the nonspatial version of the Morris water maze of rats given anisomycin $(160 \mu \mathrm{g} /$ side; ANI, black circles) or vehicle $(\mathrm{VEH}$, gray circles) in the CA1 region of the dorsal hippocampus. The arrow indicates the moment of infusion. Data are presented as mean ( \pm SEM); $F_{(1,14)}=0.69 ; P>0.1$ during Session 2 in two-way ANOVA; $n=8$ per group. $(H)$ representative photomicrograph (top) and schematic drawing used with permission from Elsevier (c) 1986, from the atlas of Paxinos and Watson (1986) (bottom) showing the infusion site in dorsal CA1. 
ery of the spatial memory when given into dorsal CA1 after a series of consecutive nonreinforced retrieval sessions.

4. When injected into dorsal CA1 after reversal learning, ANI blocks retention of the reversed preference, but this blockade does not result in reinstatement of the original spatial memory.

\section{Anisomycin and spatial memory consolidation}

It has been demonstrated that inhibition of protein synthesis in different areas of the brain impairs memory consolidation of different tasks in species ranging from mollusks and arthropods to birds and mammals (Gibbs and Ng 1978; Barraco et al. 1981; Staubli et al. 1985; Crow and Forrester 1990; Pedreira et al. 1996; Grunbaum and Muller 1998; Ramirez et al. 1998; Wustenberg et al. 1998; Epstein et al. 2003; Ezzeddine and Glanzman 2003).

Most findings indicate the existence of a critical time window for protein synthesis during or immediately after training, although some reports also point to a second phase of sensitivity of memory to protein synthesis inhibition 3-6 h post-training (Grecksch and Matthies 1980; Freeman et al. 1995). In total agreement with previous findings showing that ANI completely blocks spatial memory in the MWM when given in the lateral ventricle at the time of training but not later (Meiri and Rosenblum 1998), our experiments indicate that retention of this type of memory requires protein synthesis in the dorsal hippocampus during a restricted period that initiates right after training and lasts $<3 \mathrm{~h}$ (Fig. 1).

The fact that intra-CA1 ANI did not affect retention of the nonspatial version of the MWM, and that the effect of this drug on spatial memory was time-dependent and reversible, clearly indicates that the observed amnesia was not due to a permanent insult to hippocampal functionality or to impaired performance but to a bonafide inhibitory action of ANI on the consolidation process.

Intra-hippocampal anisomycin and the stability of reactivated spatial memory traces

Broadly stated, consolidation theory postulates that, once acquired, memories undergo a stabilization process involving plastic modifications in synaptic efficacy and connectivity that make the trace resistant to interferences (McGaugh 1966). It is obvious that consolidated memories are not immutable: Changes can be induced by false leads, additional learning, and neurohumoral influences during retrieval (Loftus and Palmer 1974; Izquierdo 1989; Schacter and Dodson 2001). Consolidation theory alone, however, does not predict the existence of a specific mechanism to account for these observations. Based on find-
A
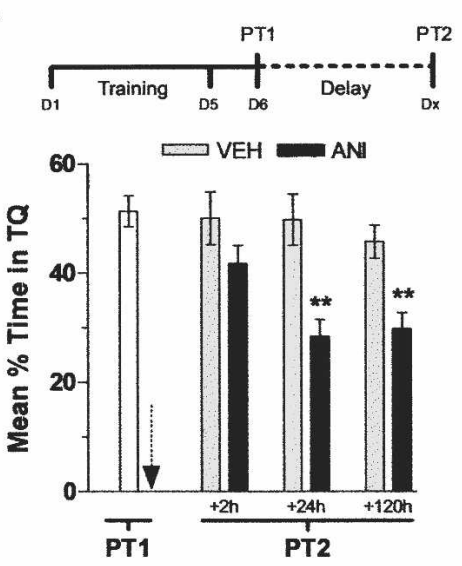

C
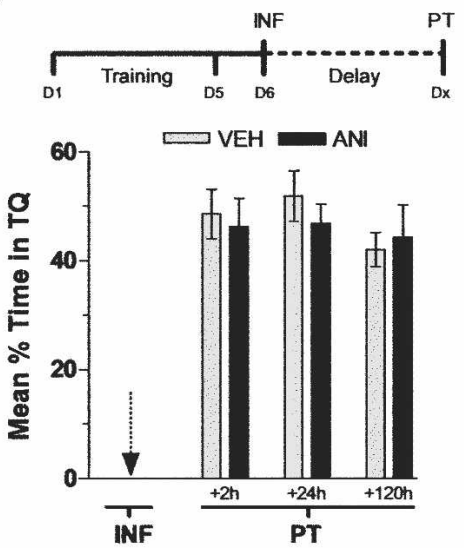

E
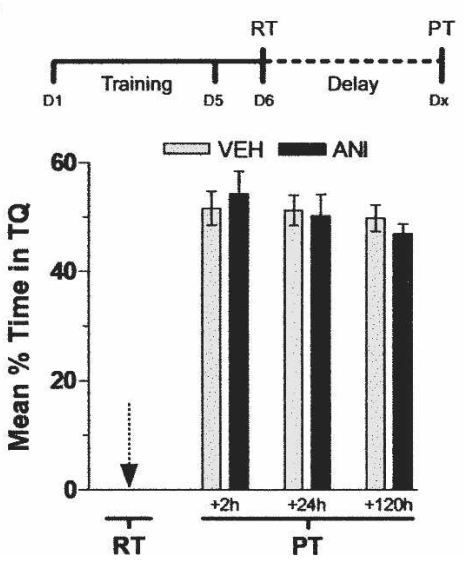

D
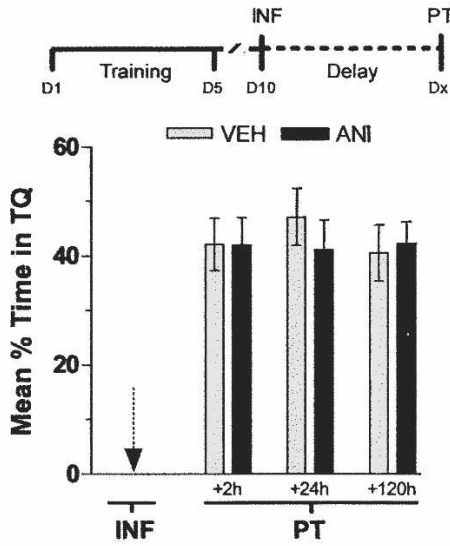

F

B
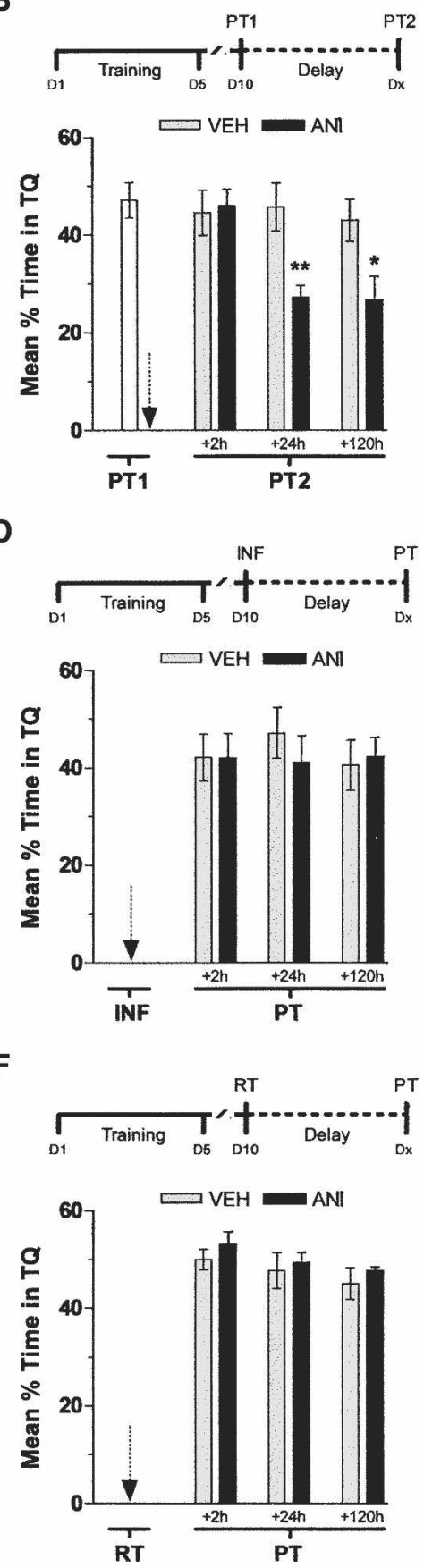

Figure 2. (Legend on next page) 
ting: If it is interrupted for $\geq 1 \mathrm{~d}$, the original response usually recovers spontaneously (Pavlov 1927).

It has been suggested that extinction and reconsolidation are competing processes and that the process that prevails to dominate future behavior is the one ultimately affected by protein synthesis inhibition (Nader 2003; Dudai 2004). The competition between extinction and reconsolidation seems to depend on the length and/or number of memory reactivation sessions (Pedreira and Maldonado 2003). A brief re-exposure, like that caused by a short retrieval session, would induce reconsolidation, whereas longer or repeated reminder trials would result in extinction (Debiec et al. 2002; Eisenberg et al. 2003).

We found that a single nonreinforced reactivation trial in the MWM, unable to initiate extinction, is enough to return the spatial memory trace to a phase during which it is vulnerable to hippocampal protein synthesis inhibition (Fig. 2). The amnesic action of intra-hippocampal ANI was found to be timedependent, required $>2 \mathrm{~h}$ to take hold, was seen only after nonreinforced reactivation, lasted for several days, and was independent of the age of the memory being reactivated (Figs. 2, 3), suggesting that it was not caused by a delayed inhibitory effect on retrieval, but probably was due to inhibition of a process that stabilizes the retrieved trace.

\section{Intra-hippocampal anisomycin and extinction of spatial memory}

We also found that as the number of consecutive reactivation trials increases, so does the likelihood of inducing long-term extinction of spatial memory. One reactivation trial did not cause extinction. Four or eight trials induced incomplete extinction, as demonstrated by the fact that the learned spatial preference reappeared spontaneously. Sixteen trials induced a deeper extinction, after which there was no spontaneous recovery $1 \mathrm{~d}$ later (Fig. 4). However, although it has been reported that systemic ANI given before MWM memory reactivation blocks either reconsolidation or extinction depending on the number of nonreinforced tests (Suzuki et al. 2004), we found that intrahippocampal ANI did not affect spatial memory extinction after 16 trials. Instead, ANI blocked the spontaneous recovery of the initial memory that happened after four or eight consecutive probe tests (Fig. 4).

These results have multiple implications. To begin with, they support the reconsolidation hypothesis as proposed by Sara
(2000) and Nader et al. (2000a,b). They do not necessarily endorse the notion that extinction and reconsolidation are competing processes (Nader 2003; Dudai 2004; Eisenberg and Dudai 2004), at least concerning hippocampal protein synthesis at the time of retrieval. Here, unlike other tasks (Vianna et al. 2001), extinction seems not to depend on hippocampal protein synthesis; reconsolidation, instead, does depend on it.

In addition, and importantly, the present results also suggest that spontaneous recovery is not an unstructured phenomenon that merely reflects the re-emergence of the original memory, because that memory may regain strength in the context of a determined set of retrieval cues. Such a comeback would not require protein synthesis in the CA1 region of the hippocampus to occur. Here, we found that hippocampal protein synthesis inhibition does regulate the eventual occurrence of spontaneous recovery, and that this depends on the number of previous training trials. Others have shown it to be also dependent on the interval between acquisition and extinction and on the number of extinction trials (Sandoz and Pham-Delègue 2004).

In fact, we have recently shown that extinction can be made so complete that, afterward, there is no spontaneous recovery, and relearning the original task requires protein synthesis as if the animals had to learn the task anew (Cammarota et al. 2003). This suggests that, under certain circumstances, repeated reactivation without reinforcement may indeed produce extinction by attenuating some aspect of the pre-existing association, as proposed earlier (Robbins 1990). If viewed from this perspective, our present results could be taken as an indication that the fate of a spatial memory reactivated in the absence of reinforcement depends on the number of re-exposures. If this number is not enough to induce long-term extinction, then part of the trace is preserved and can be rebuilt through a protracted hippocampal protein synthesis-dependent reconsolidation process that results in the spontaneous recovery of the original memory. Conversely, when the number of nonreinforced reactivation sessions surpasses a certain threshold, the original response cannot be reconsolidated any more and becomes extinguished.

In a recent study on spontaneous recovery of appetitive learning in the honeybee, Stollhoff et al. (2005) showed that the protein synthesis inhibitor emetine does not affect extinction but inhibits spontaneous recovery after five extinction trials; they concluded that this spontaneous recovery resulted from reconsolidation of the original response. Further experiments will be needed to ascertain the real nature of spontaneous recovery.

\footnotetext{
Figure 2. Inhibition of hippocampal protein synthesis immediately after nonreinforced retrieval hinders spatial memory retention. $(A)$ Animals with infusion cannulae implanted in the CA1 region of the dorsal hippocampus were trained during $5 \mathrm{~d}$ in the spatial version of the MWM (D1-D5) Twenty-four hours later (D6), animals were randomly assigned to one out of six experimental groups and submitted to a 60-sec probe test in the absence of the escape platform (PT1). Immediately after PT1, animals received intra-CA1 infusions of anisomycin (160 $\mu \mathrm{g} / \mathrm{side}$; ANI) or vehicle (VEH). The black arrow indicates the moment of infusion. Memory retention was assessed in a second 60-sec probe test (PT2) carried out either at 2, 24, or 120 h after PT1. Data are expressed as mean ( \pm SEM) percentage of time swimming in the target quadrant $(T Q) ;{ }^{* *} P<0.01$ vs. VEH during PT2 carried out at 24 $\mathrm{h}\left(+24 \mathrm{~h} ; t_{[12]}=3.80\right)$ or $120 \mathrm{~h}\left(+120 \mathrm{~h} ; t_{[12]}=3.73\right)$ after PT1; $P>0.1 \mathrm{vs}$. VEH during PT2 carried out $2 \mathrm{~h}$ after PT1 $\left(+2 \mathrm{~h} ; t_{[12]}=1.41\right)$. In all cases $n=7$ per group. (B) Animals were treated exactly as in $A$ except that PT1 was carried out $120 \mathrm{~h}(\mathrm{D} 10)$ after the last training session. ${ }^{* *} P<0.01 \mathrm{vs}$. VEH during PT2 carried out $24 \mathrm{~h}$ after PT1 $\left(+24 \mathrm{~h} ; t_{[12]}=3.38\right) ;{ }^{*} P<0.05$ vs. VEH during PT2 carried out $120 \mathrm{~h}$ after PT1 $\left(+120 \mathrm{~h} ; t_{[12]}=2.51\right) ; P>0.05$ vs. VEH during PT2 carried out $2 \mathrm{~h}$ after PT1 $\left(+2 \mathrm{~h} ; t_{[12]}=0.25\right)$. In all cases $n=7$ per group. (C) Animals with infusion cannulae implanted in the CA1 region of the dorsal hippocampus were trained during $5 \mathrm{~d}$ in the spatial version of the MWM (D1-D5). Twenty-four hours later (D6), animals were randomly assigned to one out of six experimental groups and received intra-CA1 infusions (INF) of anisomycin ( $160 \mu \mathrm{g} / \mathrm{side}$; ANI) or vehicle (VEH). The black arrow indicates the moment of infusion. Memory retention was assessed in a $60-\mathrm{sec}$ probe test (PT) carried out at either $2 \mathrm{~h}\left(+2 \mathrm{~h} ; P>0.1 \mathrm{vs}\right.$. VEH, $\left.t_{[12]}=0.33\right)$, $24 \mathrm{~h}\left(+24 \mathrm{~h} ; P>0.1\right.$ vs. VEH, $\left.t_{[12]}=0.85\right)$, or $120 \mathrm{~h}\left(+120 \mathrm{~h} ; P>0.1\right.$ vs. VEH, $\left.t_{[12]}=0.34\right)$ after INF. Data are expressed as mean $( \pm S E M)$ percentage of time swimming in the target quadrant (TQ). In all cases $n=7$ per group. (D) Animals were treated exactly as in $C$ except that INF was carried out $120 \mathrm{~h}(\mathrm{D} 10)$ after the last training session; $P>0.1 \mathrm{vs}$. VEH during a PT carried out at $2 \mathrm{~h}\left(+2 \mathrm{~h} ; t_{[12]}=0.02\right), 24 \mathrm{~h}\left(+24 \mathrm{~h} ; t_{[12]}=0.79\right)$, or $120 \mathrm{~h}(+120$ $\left.\mathrm{h} ; t_{[12]}=0.26\right)$ after INF. In all cases $n=7$ per group. $(E)$ Animals with infusion cannulae implanted in the CA1 region of the dorsal hippocampus were trained during $5 \mathrm{~d}$ in the spatial version of the MWM (D1-D5). Twenty-four hours later (D6), animals were randomly assigned to one out of six experimental groups and submitted to a retraining test (RT) in the presence of the escape platform. Immediately after RT, animals received intra-CA1 infusions of anisomycin $(160 \mathrm{\mu g} / \mathrm{side}$; ANI) or vehicle (VEH). The black arrow indicates the moment of infusion. Memory retention was assessed in a probe test (PT) carried out either at $2 \mathrm{~h}\left(+2 \mathrm{~h} ; P>0.1 \mathrm{vs}\right.$. VEH, $\left.t_{[14]}=0.42\right), 24 \mathrm{~h}\left(+24 \mathrm{~h} ; P>0.1 \mathrm{vs}\right.$. VEH, $\left.t_{[14]}=0.01\right)$, or $120 \mathrm{~h}(+120 \mathrm{~h} ; P>0.1 \mathrm{vs}$. VEH, $\left.t_{[14]}=1.44\right)$ after RT. Data are expressed as mean ( \pm SEM) percentage of time swimming in the target quadrant (TQ). In all cases $n=8$ per group. ( $F$ ) Animals were treated exactly as in $E$ except that RT was carried out $120 \mathrm{~h}$ (D10) after the last training session; $P>0.1 \mathrm{vs.} \mathrm{VEH} \mathrm{during} \mathrm{a} \mathrm{PT} \mathrm{carried} \mathrm{out}$ at $2 \mathrm{~h}\left(+2 \mathrm{~h} ; t_{[14]}=0.81\right), 24 \mathrm{~h}\left(+24 \mathrm{~h} ; t_{[14]}=0.20\right)$, or $120 \mathrm{~h}\left(+120 \mathrm{~h} ; t_{[14]}=0.28\right)$ after INF. In all cases $n=8$ per group.
} 
A
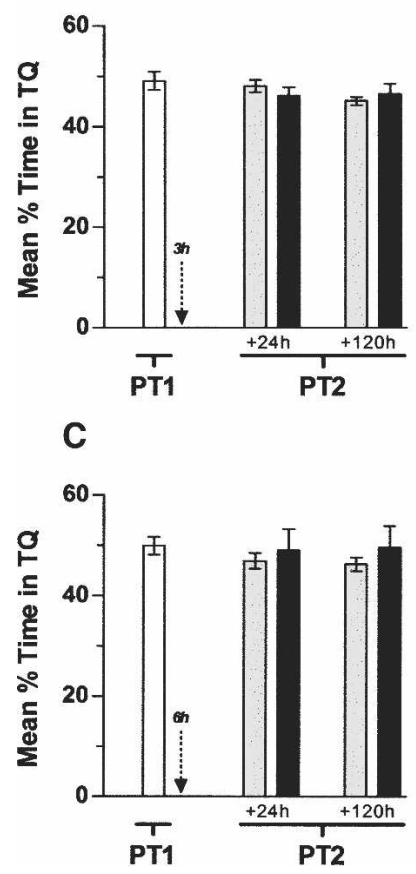

B

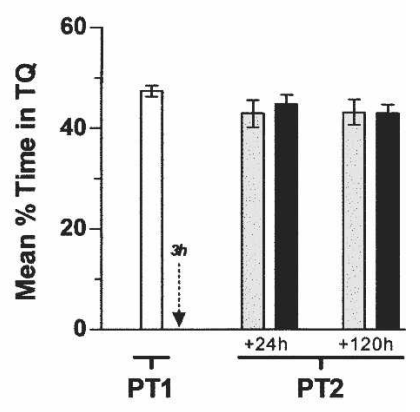

D

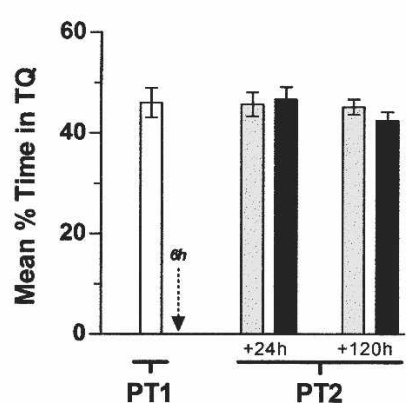

Figure 3. Inhibition of hippocampal protein synthesis 3 or $6 \mathrm{~h}$ after nonreinforced retrieval does not affect spatial memory retention. $(A)$ Animals with infusion cannulae implanted in the CA1 region of the dorsal hippocampus were trained during $5 \mathrm{~d}$ in the spatial version of the MWM. Twenty-four hours later, the animals were randomly assigned to one out of four experimental groups and submitted to a $60-\mathrm{sec}$ probe test in the absence of the escape platform (PT1). Three hours after PT1, animals received intra-CA1 infusions of anisomycin $(160 \mu \mathrm{g} / \mathrm{side}$; $\mathrm{ANI})$ or vehicle (VEH). The black arrow indicates the moment of infusion. Memory retention was assessed in a second 60 -sec probe test (PT2) carried out either 24 or $120 \mathrm{~h}$ after PT1. Data are expressed as mean ( \pm SEM) percentage of time swimming in the target quadrant (TQ). $P>0.1 \mathrm{vs.} \mathrm{VEH} \mathrm{during} \mathrm{a} \mathrm{PT2}$ carried out at $24 \mathrm{~h}\left(+24 \mathrm{~h} ; t_{[16]}=0.92\right)$ or $120 \mathrm{~h}\left(+120 \mathrm{~h} ; t_{[16]}=0.67\right)$ after PT1; $n=9$ per group. (B) Animals were treated exactly as in $A$ except that PT1 was carried out $120 \mathrm{~h}$ after the last training session. The black arrow indicates the moment of infusion. $P>0.1 \mathrm{vs}$. VEH during a PT2 carried out at $24 \mathrm{~h}\left(+24 \mathrm{~h} ; t_{[14]}=0.57\right)$ or $120 \mathrm{~h}\left(+120 \mathrm{~h} ; t_{[14]}=0.08\right)$ after PT1; $n=8$ per group. (C) Animals with infusion cannulae implanted in the $C A 1$ region of the dorsal hippocampus were trained during $5 \mathrm{~d}$ in the spatial version of the MWM. Twenty-four hours later, the animals were randomly assigned to one out of four experimental groups and submitted to a 60 -sec probe test in the absence of the escape platform (PT1). Six hours after PT1, animals received intra-CA1 infusions of anisomycin $(160 \mu \mathrm{g} / \mathrm{side} ; \mathrm{ANI})$ or vehicle (VEH). The black arrow indicates the moment of infusion. Memory retention was assessed in a second 60-sec probe test (PT2) carried out 24 or $120 \mathrm{~h}$ after PT1. Data are expressed as mean $( \pm$ SEM) percentage of time swimming in the target quadrant (TQ). $P>0.1$ vs. VEH during PT2 at $24 \mathrm{~h}\left(+24 \mathrm{~h} ; t_{[16]}=0.47\right)$ or $120 \mathrm{~h}$ $\left(+120 \mathrm{~h} ; t_{[16]}=0.74\right)$ after PT1; $n=9$ per group. $(D)$ Animals were treated exactly as in C except that PT1 was carried out $120 \mathrm{~h}$ after the last training session. The black arrow indicates the moment of infusion. $P>0.1$ vs. VEH during a PT2 carried out at either $24 \mathrm{~h}\left(+24 \mathrm{~h} ; t_{[14]}=0.29\right)$ or $120 \mathrm{~h}$ $\left(+120 \mathrm{~h} ; t_{[14]}=1.21\right)$ after PT1; $n=8$ per group.

Our results contradict those of Lattal and Abel (2001), who found that in mice subcutaneous injection of ANI at the time of re-exposure to the MWM had no effect on subsequent memory retention. This negative result has been previously attributed to the length of the re-exposure session used (Suzuki et al. 2004) and, like other discrepancies found in the literature, might also be related to the fact that the effects of protein synthesis inhibitors on memory processing are highly dependent on methodological issues, including time and way of administration and the

task and species studied. This observation could be quite important when comparing results in the MWM since mice show a very different behavioral response than rats when exposed to the training pool. In particular, floating and thigmotaxis tend to be more pronounced in mice than in rats, which may complicate testing (D'Hooge and De Deyn 2001).

\section{Is reconsolidation involved in reversal learning?}

Notwithstanding how straightforward the interpretation of our results might seem, it must be noted that they were obtained using a behavioral protocol that, if repeated enough, induces the behavioral disappearance of the learned response. Is there any behavioral paradigm capable of inducing spatial memory reconsolidation as the primary outcome, or is this process secondary to the incomplete extinction of the original spatial preference?

During reversal spatial learning, animals redirect the original response and learn to swim to a different quadrant. This has been suggested to involve a special form of extinction of the original memory that is expressed as a new spatial preference (Lattal et al. 2004). This interpretation does not exclude other possibilities. Acquisition of the reversed response is faster than original learning, suggesting that, probably, many of the nonspatial components of the original trace do not extinguish during reversal learning but are used as a basis on which the original spatial trace is first weakened and later changed and stabilized into a reversed preference. If viewed from this angle, reversal learning may be considered to involve reconsolidation of the original response, a process that in the case of a real-life situation would be extremely adaptive.

We found that ANI given immediately after reversal learning not only blocked formation of the reversed preference but also hindered persistence of the original memory (Fig. 5). If the amnesic effect of ANI on reversal learning had merely been due to inhibition of extinction of the original memory, the original spatial preference should have reappeared. This should also have happened if the strength and stability of the original trace were independent of a hippocampal protein synthesis-dependent process initiated by reversal learning. As seen in Figure 5, this was not the case. Moreover, 1 or $5 \mathrm{~d}$ after eight consecutive reversal learning trials there was no inkling of a spontaneous recovery of the original spatial preference in control animals (Fig. 5). This was contrary to what was seen after eight extinction trials (Fig. 4), and suggests, therefore, that reversal learning does not rely only on extinction.

Our findings support the idea that reversal learning consists of reconsolidation of the original response with a new spatial cue rather than extinction and suggests that perhaps reconsolidation is induced not only when nonreinforced retrieval is ineffective to induce long-lasting extinction, but also when the reinforcer, even if present, does not match exactly the expectations derived from previous learning. In this respect, Rodriguez-Ortiz et al. (2005) have proposed that the reconsolidation process would be part of a mechanism able to incorporate updated information into previously consolidated memories.

\section{Conclusions}

Before ending, a cautionary comment is needed. The experiments presented here, like the majority of the results supporting the reconsolidation hypothesis, were obtained using the antibiotic ANI. As with most any other pharmacological agent, ANI has side effects. Therefore, an action other than protein synthesis inhibition could be responsible for any amnesia that this drug can produce. This has been recently pointed out by Rudy et al. (2006) and previously by Routtenberg and Rekart (2005). It is 
A

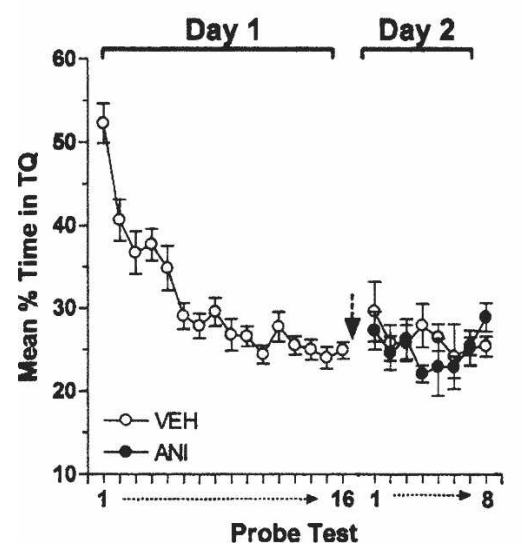

B

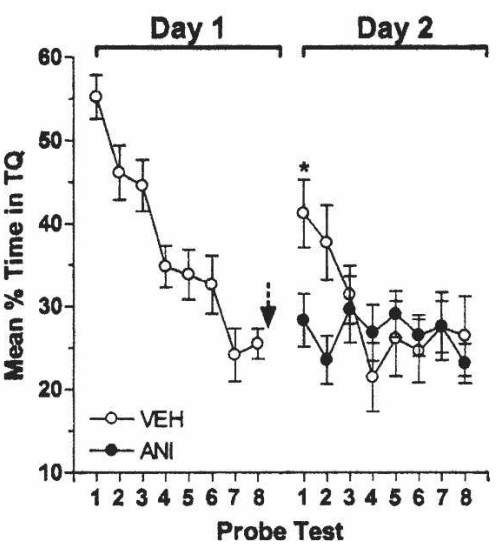

C

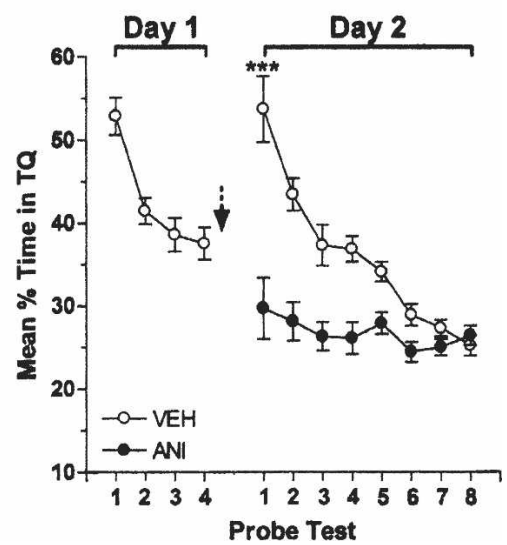

Figure 4. Inhibition of hippocampal protein synthesis does not affect extinction but blocks spontaneous recovery of spatial memory. Animals with infusion cannulae implanted in the CA1 region of the dorsal hippocampus were trained during $5 \mathrm{~d}$ in the spatial version of the MWM and $24 \mathrm{~h}$ after the last training session were submitted to either $16(A)$, eight $(B)$, or four $(C)$ consecutive probe tests (extinction trials) in the absence of the escape platform (Day 1). Immediately following the last probe test, the animals received intra-CA1 infusions of anisomycin (160 $\mu$ g/side; ANI) or vehicle. The black arrow indicates the moment of infusion. Retention of extinction was assessed during eight additional probe tests carried out $24 \mathrm{~h}$ later (Day 2 ). Data are expressed as mean $\left( \pm\right.$ SEM) percentage of time swimming in the target quadrant $(\mathrm{TQ}) ;{ }^{* * *} P<0.001$ and ${ }^{*} P<0.05$ vs. VEH in the first test of Day $2 ; n=8-11$ per group.

important to mention, however, that the caveats generated by the use of ANI to analyze the reconsolidation hypothesis do not apply only to this process but also to other memory and plasticity events, including consolidation, extinction, and long-term potentiation. At the dose we used, ANI does block hippocampal protein synthesis (Cammarota et al. 2004). The possibility that the observed amnesia was due to any deleterious effect of this drug on hippocampal functionality was discarded with the proper control experiments. However, our experiments cannot conclusively rule out the possibility that the amnesia induced by post-retrieval infusion of ANI in the CA1 region of the dorsal hippocampus represents just a temporary performance effect. Methodological constraints inherent to the task and to survival of cannulated animals prevented us from testing retrieval for longer periods than those reported.

In conclusion, our results indicate that consolidation of spatial memory requires hippocampal protein synthesis during a restricted post-training time window. They also suggest that retrieval labilizes spatial memory, but when nonreinforced expression is insufficient to induce long-term extinction, the weakened trace recovers through a hippocampal-dependent reconsolidation process that is blocked by ANI given into dorsal CA1 at the time of memory reactivation. In addition, our data indicate that inhibition of hippocampal protein synthesis does not affect spatial memory extinction but hinders reversal learning in a timedependent, long-lasting manner, probably due to blockade of original memory reconsolidation.

\section{Materials and Methods}

\section{Subjects, surgery, and drug infusion procedures}

Three-month-old male Wistar rats weighing 220-280 g and bred in our animal facility were used in the experiments. Animals were housed four to a cage and maintained at $22^{\circ} \mathrm{C}-23^{\circ} \mathrm{C}$ under a $12-\mathrm{h}$ light/12-h dark cycle (lights on at 7:00 a.m.) with free access to food and water. To implant them with indwelling cannulae, rats were deeply anesthetized with thiopental (30-50 mg/Kg, i.p.), and 27-gauge cannulae were stereotaxically aimed to the pyramidal cell layer of the dorsal CA1 region using coordinates (A -4.2, L $\pm 3.0, \mathrm{~V}$ 1.4) taken from the atlas of Paxinos and Watson (1986). Animals were allowed to recover from surgery during $4 \mathrm{~d}$ before submitting them to any other procedure. At the time of drug delivery, a 30-gauge infusion cannula was tightly fitted into the guides. Infusions $(0.8 \mu \mathrm{L} / \mathrm{side})$ were carried out over $60 \mathrm{sec}$, first on one side and then on the other; the infusion cannulas were left in place for 30 additional seconds to minimize backflow. Cannulae placement was verified postmortem: $2-4 \mathrm{~h}$ after the last behavioral test, $0.8 \mu \mathrm{L}$ of a $4 \%$ methylene-blue solution was infused as described above, and the extension of the dye 30 min thereafter was taken as indicative of the presumable diffusion of the vehicle or drug previously given to each animal. A total of 760 animals were used. Only data from animals with correct cannulae implants (717 animals; $94.3 \%$ of the total) were included in the statistical analyses. All experiments were conducted blind to the treatment condition of the animals and fol-
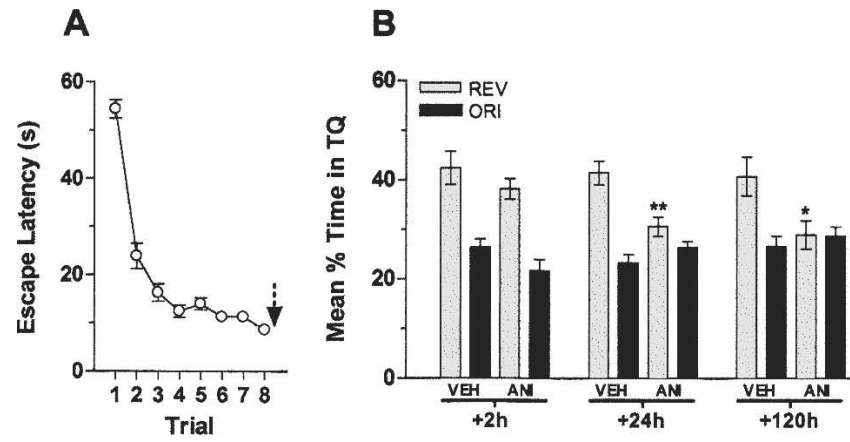

Figure 5. Inhibition of hippocampal protein synthesis blocks reversal learning and hinders reinstatement of the original spatial memory. Animals with infusion cannulae implanted in the CA1 region of the dorsal hippocampus were trained during $5 \mathrm{~d}$ in the spatial version of the MWM and $24 \mathrm{~h}$ after the last training session were submitted to eight consecutive reversal learning trials. $(A)$ Mean escape latency $( \pm S E M)$ to find the escape platform during reversal training. Immediately following the last reversal trial, animals received intra-CA1 infusions of anisomycin (160 $\mu \mathrm{g} / \mathrm{side}$; $\mathrm{ANI}$ ) or vehicle; the black arrow indicates the moment of infusion. Memory retention was evaluated in a probe test carried out either at 2,24 , or $120 \mathrm{~h}$ after reversal learning. (B) Spatial preference during a 60 -sec probe test for rats given intra-CA1 anisomycin $(160 \mu \mathrm{g} / \mathrm{side}$; ANI) or vehicle (VEH) immediately after reversal learning. Data are expressed as mean $( \pm$ SEM) percentage of time swimming in the original $(O R I)$ and opposite/reversal (REV) quadrant. ${ }^{* *} P<0.01$ and ${ }^{*} P<0.05$ vs. VEH; $n=11-19$ per group. 
lowing the National Institutes of Health of the USA guidelines for animal care and use and were approved by the Animal Care and Ethical Committees of the University of Buenos Aires and of the Pontifical Catholic University of Rio Grande do Sul.

\section{Drugs}

Anisomycin (ANI) was purchased from Sigma and was first dissolved in $1 \mathrm{~N} \mathrm{HCl}$, the $\mathrm{pH}$ adjusted to $\sim 7$ with $1 \mathrm{~N} \mathrm{NaOH}$, and further diluted to final concentration with saline. ANI was infused in the CA1 region at $160 \mu \mathrm{g} /$ side.

\section{Apparatus and training in the spatial version of the MWM}

The water maze was a black circular pool $(200 \mathrm{~cm}$ in diameter) conceptually divided into four equal imaginary quadrants for the purpose of data analysis. The water temperature was $21^{\circ} \mathrm{C}-23^{\circ} \mathrm{C}$. Two centimeters beneath the surface of the water and hidden from the rat's view was a black circular platform $(12 \mathrm{~cm}$ in diameter). It had a rough surface, which allowed the rat to climb onto it easily once its presence was detected. The swimming path of the rats was recorded using a video camera mounted above the center of the pool and analyzed using a video tracking and analysis system. The water maze was located in a well lit white room with several posters and other distal visual stimuli hanging on the walls to provide spatial cues. A curtain separated the water maze room from the room where the computer setup was installed and where the animals were temporarily housed during the behavioral sessions. Rats were handled 5 min per day for $3 \mathrm{~d}$ prior to training. Training in the hidden platform (spatial) version of the MWM was carried out during 5 consecutive days. On each day, rats received eight consecutive training trials during which the hidden platform was kept in a constant location. A different starting location was used on each trial, which consisted of a swim followed by a 30-sec platform sit. Any rat that did not find the platform within $60 \mathrm{sec}$ was guided to it by the experimenter. The intertrial interval (ITI) was $30 \mathrm{sec}$. During the ITI, rats were carefully dried with a towel by the experimenter. When the purpose of the experiment was to analyze the effect of protein synthesis inhibition on the formation of the MWM memory, immediately, $3 \mathrm{~h}$, or $6 \mathrm{~h}$ after the eighth trial in each training day rats were dried and moved to the injection room where they received bilateral intra-CA1 infusions of ANI or vehicle (saline). Memory retention was evaluated in a 60 -sec probe trial carried out in the absence of the escape platform $24 \mathrm{~h}$ after the last training session. To evaluate the effect of ANI when given after memory reactivation, rats were trained for $5 \mathrm{~d}$ as indicated above before being submitted to a probe test in the absence of the escape platform either 24 or $120 \mathrm{~h}$ after the last training session. Immediately, $3 \mathrm{~h}$, or $6 \mathrm{~h}$ after that, rats received intra-CA 1 infusions of ANI or vehicle. Memory retention was evaluated in a second probe test carried out either 2,24 , or $120 \mathrm{~h}$ after the first one.

\section{Extinction}

To analyze extinction of the spatial preference, rats were trained in the spatial version of the MWM during $5 \mathrm{~d}$ as stated above, and $24 \mathrm{~h}$ after the last training session were submitted to four, eight, or 16 consecutive 60 -sec probe tests (extinction trials) in the absence of the escape platform. Immediately after the last extinction trial, rats received bilateral intra-CA1 infusions of either ANI or vehicle. To evaluate the retention of extinction, $24 \mathrm{~h}$ later rats were submitted to eight additional extinction trials.

\section{Reversal learning}

Rats were trained in the spatial version of the MWM during $5 \mathrm{~d}$ as stated above, and $24 \mathrm{~h}$ after the last training session were submitted to eight 60 -sec reversal trials in which the platform was placed in the opposite quadrant of the pool. Immediately after the last reversal trial, animals received intra-CA1 infusions of ANI or vehicle. Memory retention was evaluated in a probe test carried out either at 2, 24, or $120 \mathrm{~h}$ after the last reversal trial.

\section{Training in the nonspatial version of the MWM}

For training in the nonspatial version of the MWM task, we used the same tank employed for training in the spatial version of the task but surrounded it by a black curtain so there were no extrapool spatial cues available. A white circular disk $10 \mathrm{~cm}$ in diameter was mounted on top of the hidden platform so it was $10 \mathrm{~cm}$ above the water surface, indicating the position of the platform. Training in the cued version of the MWM was carried out during 2 consecutive days. On each day rats received eight consecutive 60 -sec training trials with a 30 -sec ITI. Both the starting location and the position of the platform were changed on each trial. Infusion of drugs was performed as stated above.

\section{Statistical analysis}

Data were analyzed by a two-tailed Student's $t$-test, repeated measures ANOVA, or a two-way ANOVA followed by Bonferroni posttests, as appropriate.

\section{Acknowledgments}

This work was supported by grants from CNPq, CAPES, and FAPERGS (Brasil), and CONICET and ANPCyT (Argentina).

\section{References}

Anokhin, K.V., Tiunova, A.A., and Rose, S.P. 2002. Reminder effects-Reconsolidation or retrieval deficit? Pharmacological dissection with protein synthesis inhibitors following reminder for a passive-avoidance task in young chicks. Eur. J. Neurosci. 15: $1759-1765$.

Bahar, A., Samuel, A., Hazvi, S., and Dudai, Y. 2003. The amygdalar circuit that acquires taste aversion memory differs from the circuit that extinguishes it. Eur. J. Neurosci. 17: 1527-1530.

Barraco, D.A., Lovell, K.L., and Eisenstein, E.M. 1981. Effects of cycloheximide and puromycin on learning and retention in the cockroach, P. americana. Pharmacol. Biochem. Behav. 15: 489-494.

Biedenkapp, J.C. and Rudy, J.W. 2004. Context memories and reactivation: Constraints on the reconsolidation hypothesis. Behav. Neurosci. 118: 956-964.

Bures, J., Fenton, A.A., Kaminsky, Y., and Zinyuk, L. 1997. Place cells and place navigation. Proc. Natl. Acad. Sci. 94: 343-350.

Cammarota, M., Bevilaqua, L.R., Kerr, D., Medina, J.H., and Izquierdo, I. 2003. Inhibition of mRNA and protein synthesis in the CA1 region of the dorsal hippocampus blocks reinstallment of an extinguished conditioned fear response. I. Neurosci. 23: 737-741.

Cammarota, M., Bevilaqua, L.R., Medina, J.H., and Izquierdo, I. 2004. Retrieval does not induce reconsolidation of inhibitory avoidance memory. Learn. Mem. 11: 572-578.

Crow, T. and Forrester, J. 1990. Inhibition of protein synthesis blocks long-term enhancement of generator potentials produced by one-trial in vivo conditioning in Hermissenda. Proc. Natl. Acad. Sci. 87: 4490-4494.

Dawson, R.G. and McGaugh, J.L. 1969. Electroconvulsive shock effects on a reactivated memory trace: Further examination. Science 166: $525-527$.

Debiec, J., LeDoux, J.E., and Nader, K. 2002. Cellular and systems reconsolidation in the hippocampus. Neuron 36: 527-538.

De Hoz, L., Martin, S.J., and Morris, R.G. 2004. Forgetting, reminding, and remembering: The retrieval of lost spatial memory. PLOS Biol. 2: E225.7.

D'Hooge, R. and De Deyn, P.P. 2001. Applications of the Morris water maze in the study of learning and memory. Brain Res. Brain Res. Rev. 36: 60-90.

Dudai, Y. 2002. Molecular bases of long-term memories: A question of persistence. Curr. Opin. Neurobiol. 12: 211-216. . 2004. The neurobiology of consolidations, or, how stable is the engram? Annu. Rev. Psychol. 55: 51-86.

Eisenberg, M. and Dudai, Y. 2004. Reconsolidation of fresh, remote, and extinguished fear memory in Medaka: Old fears don't die. Eur. J. Neurosci. 20: 3397-3403.

Eisenberg, M., Kobilo, T., Berman, D.E., and Dudai, Y. 2003. Stability of retrieved memory: Inverse correlation with trace dominance. Science 301: 1102-1104.

Epstein, H.T., Child, F.M., Kuzirian, A.M., and Alkon, D.L. 2003. Time windows for effects of protein synthesis inhibitors on Pavlovian conditioning in Hermissenda: Behavioral aspects. Neurobiol. Learn. Mem. 79: 127-131.

Ezzeddine, Y. and Glanzman, D.L. 2003. Prolonged habituation of the gill-withdrawal reflex in Aplysia depends on protein synthesis, 
protein phosphatase activity, and postsynaptic glutamate receptors. J. Neurosci. 23: 9585-9594.

Fischer, A., Sananbenesi, F., Schrick, C., Spiess, J., and Radulovic, J. 2004. Distinct roles of hippocampal de novo protein synthesis and actin rearrangement in extinction of contextual fear. J. Neurosci. 24: $1962-1966$.

Freeman, F.M., Rose, S.P., and Scholey, A.B. 1995. Two time windows of anisomycin-induced amnesia for passive avoidance training in the day-old chick. Neurobiol. Learn. Mem. 63: 291-295.

Frenkel, L., Maldonado, H., and Delorenzi, A. 2005. Memory strengthening by a real-life episode during reconsolidation: An outcome of water deprivation via brain angiotensin II. Eur. J. Neurosci. 22: 1757-1766.

Gainutdinova, T.H., Tagirova, R.R., Ismailova, A.I., Muranova, L.N., Samarova, E.I., Gainutdinov, K.L., and Balaban, P.M. 2005. Reconsolidation of a context long-term memory in the terrestrial snail requires protein synthesis. Learn. Mem. 12: 620-625.

Gibbs, M.E. and Ng, K.T. 1978. Memory formation for an appetitive visual discrimination task in young chicks. Pharmacol. Biochem. Behav. 8: 271-276.

Grecksch, G. and Matthies, H. 1980. Two sensitive periods for the amnesic effect of anisomycin. Pharmacol. Biochem. Behav. 12: $663-665$

Grunbaum, L. and Muller, U. 1998. Induction of a specific olfactory memory leads to a long-lasting activation of protein kinase $\mathrm{C}$ in the antennal lobe of the honeybee. J. Neurosci. 18: 4384-4392.

Hernandez, P.J. and Kelley, A.E. 2004. Long-term memory for instrumental responses does not undergo protein synthesis-dependent reconsolidation upon retrieval. Learn. Mem. 11: $748-754$

Horne, C.A., Rodriguez, W.A., Wright, T.P., and Padilla, J.L. 1997. Time-dependent effects of fructose on the modulation of a reactivated memory. Prog. Neuropsychopharmacol. Biol. Psychiatry 21: 649-658.

Inda, M.C., Delgado-Garcia, J.M., and Carrion, A.M. 2005. Acquisition, consolidation, reconsolidation, and extinction of eyelid conditioning responses require de novo protein synthesis. J. Neurosci. 25: $2070-2080$.

Izquierdo, I. 1989. Different forms of post-training memory processing. Behav. Neural Biol. 51: 171-202.

Izquierdo, I. and Cammarota, M. 2004. Zif and the survival of memory. Science 304: 829-830.

Judge, M.E. and Quartermain, D. 1982. Characteristics of retrograde amnesia following reactivation of memory in mice. Physiol. Behav. 28: $585-590$.

Kida, S., Josselyn, S.A., de Ortiz, S.P., Kogan, J.H., Chevere, I., Masushige, S., and Silva, A.J. 2002. CREB required for the stability of new and reactivated fear memories. Nat. Neurosci. 5: 348-355.

Lattal, K.M. and Abel, T. 2001. Different requirements for protein synthesis in acquisition and extinction of spatial preferences and context-evoked fear. J. Neurosci. 21: 5773-5780.

- 2004. Behavioral impairments caused by injections of the protein synthesis inhibitor anisomycin after contextual retrieval reverse with time. Proc. Natl. Acad. Sci. 101: 4667-4672.

Lattal, K.M., Honarvar, S., and Abel, T. 2004. Effects of post-session injections of anisomycin on the extinction of a spatial preference and on the acquisition of a spatial reversal preference. Behav. Brain Res. 153: 327-339.

Lee, J.L., Everitt, B.J., and Thomas, K.L. 2004. Independent cellular processes for hippocampal memory consolidation and reconsolidation. Science 304: 839-843.

Lewis, D.J., Bregman, N.J., and Mahan, J.J. 1972. Cue-dependent amnesia in rats. J. Comp. Physiol. Psychol. 81: 243-247.

Loftus, E.F. and Palmer, J.C. 1974. Reconstruction of automobile destruction: An example of interaction between language and memory. J. Verbal Learn. \& Verbal Behav. 13: 585-589.

Mactutus, C.F., Riccio, D.C., and Ferek, J.M. 1979. Retrograde amnesia for old (reactivated) memory: Some anomalous characteristics. Science 204: 1319-1320.

McGaugh, J.L. 1966. Time-dependent processes in memory storage. Science 153: 1351-1358.

Meiri, N. and Rosenblum, K. 1998. Lateral ventricle injection of the protein synthesis inhibitor anisomycin impairs long-term memory in a spatial memory task. Brain Res. 789: 48-55.

Merlo, E., Freudenthal, R., Maldonado, H., and Romano, A. 2005. Activation of the transcription factor NF-кB by retrieval is required for long-term memory reconsolidation. Learn. Mem. 12: 23-29.

Milekic, M.H. and Alberini, C.M. 2002. Temporally graded requirement for protein synthesis following memory reactivation. Neuron 36: $521-525$.

Mileusnic, R., Lancashire, C.L., and Rose, S.P. 2005. Recalling an aversive experience by day-old chicks is not dependent on somatic protein synthesis. Learn. Mem. 12: 615-619.

Misanin, J.R., Miller, R.R., and Lewis, D.J. 1968. Retrograde amnesia produced by electroconvulsive shock after reactivation of a consolidated memory trace. Science 160: 554-555.

Myers, K.M. and Davis, M. 2002. Behavioral and neural analysis of extinction. Neuron 36: 567-584.

Nader, K. 2003. Memory traces unbound. Trends Neurosci. 26: 65-72.

Nader, K., Schafe, G.E., and Le Doux, J.E. 2000a. Fear memories require protein synthesis in the amygdala for reconsolidation after retrieval. Nature 406: $722-726$

- 2000b. The labile nature of consolidation theory. Nat. Rev. Neurosci. 1: 216-219.

Pavlov, I.P. 1927. Conditioned reflexes. Oxford University Press, Oxford, UK.

Paxinos, G. and Watson, C. 1986. The rat brain in stereotaxic coordinates. Academic Press, San Diego, CA.

Pedreira, M.E. and Maldonado, H. 2003. Protein synthesis subserves reconsolidation or extinction depending on reminder duration. Neuron 38: 863-869.

Pedreira, M.E., Dimant, B., and Maldonado, H. 1996. Inhibitors of protein and RNA synthesis block context memory and long-term habituation in the crab Chasmagnathus. Pharmacol. Biochem. Behav. 54: $611-617$

Pedreira, M.E., Perez-Cuesta, L.M., and Maldonado, H. 2002. Reactivation and reconsolidation of long-term memory in the crab Chasmagnathus: Protein synthesis requirement and mediation by NMDA-type glutamatergic receptors. J. Neurosci. 22: 8305-8311.

Power, A.E., Berlau, D.J., McGaugh, J.L., and Steward, O. 2006. Anisomycin infused into the hippocampus fails to block "reconsolidation" but impairs extinction: The role of re-exposure duration. Learn. Mem. 13: 27-34.

Przybyslawski, J. and Sara, S.J. 1997. Reconsolidation of memory after its reactivation. Behav. Brain Res. 84: 241-246.

Przybyslawski, J., Roullet, P., and Sara, S.J. 1999. Attenuation of emotional and nonemotional memories after their reactivation: Role of $\beta$ adrenergic receptors. J. Neurosci. 19: 6623-6628.

Ramirez, R.R., Gandhi, C.C., Muzzio, I.A., and Matzel, L.D. 1998. Protein synthesis-dependent memory and neuronal enhancement in Hermissenda are contingent on parameters of training and retention. Learn. Mem. 4: 462-477.

Redish, A.D. and Touretzky, D.S. 1998. The role of the hippocampus in solving the Morris water maze. Neural Comput. 10: 73-111.

Rescorla, R.A. 2001. Retraining of extinguished Pavlovian stimuli. J. Exp. Psychol. Anim. Behav. Process. 27: 115-124.

Robbins, S.J. 1990. Mechanisms underlying spontaneous recovery in autoshaping. J. Exp. Psychol. Anim. Behav. Process. 16: 235-249.

Rodriguez, W.A., Rodriguez, S.B., Phillips, M.Y., and Martinez Jr., J.L. 1993. Post-reactivation cocaine administration facilitates later acquisition of an avoidance response in rats. Behav. Brain Res. 59: $125-129$.

Rodriguez-Ortiz, C.J., De la Cruz, V., Gutiérrez, R., and Bermudez-Rattoni, F. 2005. Protein synthesis underlies post-retrieval memory consolidation to a restricted degree only when updated information is obtained. Learn. Mem. 12: 533-537.

Routtenberg, A. and Rekart, J.L. 2005. Post-translational protein modification as the substrate for long-lasting memory. Trends Neurosci. 28: 12-19.

Rudy, J.W., Biedenkapp, J.C., Moineau, J., and Bolding, K. 2006. Anisomycin and the reconsolidation hypothesis. Learn. Mem. 13: $1-3$.

Sandoz, J.C. and Pham-Delègue, M.H. 2004. Spontaneous recovery after extinction of the conditioned proboscis extension response in the honeybee. Learn. Mem. 11: 586-597.

Sangha, S., Scheibenstock, A., Morrow, R., and Lukowiak, K. 2003. Extinction requires new RNA and protein synthesis and the soma of the cell right pedal dorsal 1 in Lymnaea stagnalis. J. Neurosci. 23: $9842-9851$.

Santini, E., Ge, H., Ren, K., Pena de Ortiz, S., and Quirk, G.J. 2004 Consolidation of fear extinction requires protein synthesis in the medial prefrontal cortex. J. Neurosci. 24: 5704-5710.

Sara, S.J. 2000. Retrieval and reconsolidation: Toward a neurobiology of remembering. Learn. Mem. 7: 73-84.

Schacter, D.L. and Dodson, C.S. 2001. Misattribution, false recognition and the sins of memory. Philos. Trans. R. Soc. Lond. B Biol. Sci. 356: $1385-1393$.

Schimanski, L.A. and Nguyen, P.V. 2004. Multidisciplinary approaches for investigating the mechanisms of hippocampus-dependent memory: A focus on inbred mouse strains. Neurosci. Biobehav. Rev. 28: $463-483$.

Squire, L.R., Slater, P.C., and Chace, P.M. 1976. Reactivation of recent or remote memory before electroconvulsive therapy does not produce retrograde amnesia. Behav. Biol. 18: 335-343. 


\section{Rossato et al.}

Staubli, U., Faraday, R., and Lynch, G. 1985. Pharmacological dissociation of memory: Anisomycin, a protein synthesis inhibitor and leupeptin, a protease inhibitor, block different learning tasks. Behav. Neural Biol. 43: 287-297.

Stollhoff, N., Menzel, R., and Eisenhardt, D. 2005. Spontaneous recovery from extinction depends on the reconsolidation of the acquisition memory in an appetitive learning paradigm in the honeybee (Apis mellifera). Neuroscience 25: 4485-4492.

Suzuki, A., Josselyn, S.A., Frankland, P.W., Masushige, S., Silva, A.J., and Kida, S. 2004. Memory reconsolidation and extinction have distinct temporal and biochemical signatures. J. Neurosci. 24: 4787-4795.

Tronson, N.C., Wiseman, S.L., Olausson, P., and Taylor, J.R. 2006. Bidirectional behavioral plasticity of memory reconsolidation depends on amygdalar protein kinase A. Nat. Neurosci. 9: 167-169. Vianna, M.R., Szapiro, G., McGaugh, J.L., Medina, J.H., and Izquierdo, I. 2001. Retrieval of memory for fear-motivated training initiates extinction requiring protein synthesis in the rat hippocampus. Proc. Natl. Acad. Sci. 98: 12251-12254.

Wustenberg, D., Gerber, B., and Menzel, R. 1998. Short communication: Long- but not medium-term retention of olfactory memories in honeybees is impaired by actinomycin D and anisomycin. Eur. J. Neurosci. 10: 2742-2745.

Received March 22, 2006; accepted in revised form May 16, 2006.

\section{Learning \& Memory} www.learnmem.org 


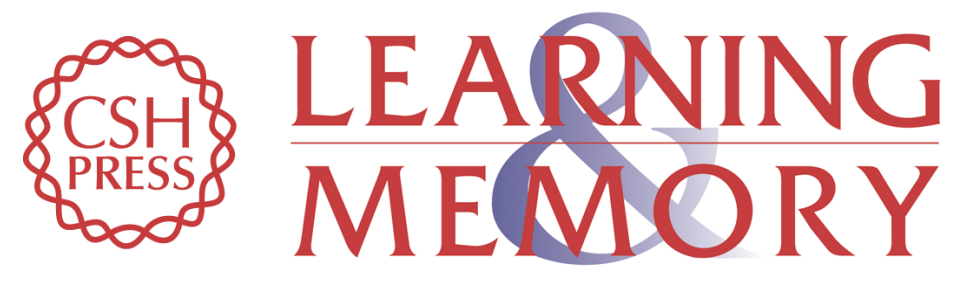

\section{Retrieval induces hippocampal-dependent reconsolidation of spatial memory}

Janine I. Rossato, Lia R.M. Bevilaqua, Jorge H. Medina, et al.

Learn. Mem. 2006, 13:

Access the most recent version at doi:10.1101/lm.315206

References This article cites 76 articles, 32 of which can be accessed free at: http://learnmem.cshlp.org/content/13/4/431.full.html\#ref-list-1

License

Email Alerting Receive free email alerts when new articles cite this article - sign up in the box at the Service top right corner of the article or click here. 